\title{
Ti/SiC Based Metal Matrix Composites by Using Self-Propagating High Temperatures Synthesis (SHS)
}

\author{
Agus Pramono ${ }^{1 *}$, Klodian Dhoska $^{2}$, Reza Moezzi $^{3}$, Anistasia Milandia $^{1}$ \\ ${ }^{1}$ Department Metallurgy, Faculty of Engineering, Universitas Sultan Ageng Tirtayasa, J1. Jenderal Sudirman Km 3, Kotabumi, \\ Kec. Purwakarta, Kota Cilegon, Banten 42435, Indonesia \\ ${ }^{2}$ Department of Production and Management, Faculty of Mechanical Engineering, Polytechnic University of Tirana, Mother \\ Theresa No. 4, Tirana 1001, Albania \\ ${ }^{3}$ Institute for Nanomaterials, Advanced Technologies and Innovations. Technical University of Liberec, Studentská 1402/2, \\ Liberec 46117, Czech Republic
}

Corresponding Author Email: agus.pramono@untirta.ac.id

https://doi.org/10.18280/rcma.310302

Received: 20 October 2020

Accepted: 11 May 2021

\section{Keywords:}

composite materials, hardness, scanning electron microscopy, X-ray diffraction, exothermic reaction

\begin{abstract}
In the present paper, $\mathrm{Ti} / \mathrm{SiC}$ composite materials have been fabricated by using Selfpropagating high temperatures synthesis (SHS). SHS is a well-known method for fabrication of the advanced materials in a single step process and is based on a system that involves an exothermic combustion. Titanium powder (Ti/p) with average particle size $100 \mu \mathrm{m}$ and Silicon carbide (SiC) with $100-320 \mu \mathrm{m}$ particle size range has been mechanically activated by attrition mill. Powder weighing has been prepared in accordance to the size of each volume fraction where the ratios for $\mathrm{Ti} / \mathrm{SiC}$ are $70: 30 \%$ and 60:40\%. The optimal density results were achieved in the volume fraction of 70:30\% at $1000^{\circ} \mathrm{C}$ for $4.54 \mathrm{gr} / \mathrm{cm}^{3}$. The porosity test data has shown that the porosity value has been increased during the increasement of the SHS sintering temperature. The lowest porosity was produced at a volume fraction of $70: 30 \%$ in a sintering temperature at $900^{\circ} \mathrm{C}$ with the corresponding value $2.36 \%$. The highest and lowest hardness value varied from $194 \mathrm{HV}$ to $40 \mathrm{HV}$. The results have shown that mechanical properties of the $\mathrm{Ti} / \mathrm{SiC}$ composite materials have been increased in comparison to the commercially pure titanium substrate and almost close to mechanical properties of $\mathrm{Al} / \mathrm{SiC}$ composite materials.
\end{abstract}

\section{INTRODUCTION}

Metal matrix composites (MMC) consists of matrix and reinforcement with ceramic phases which exhibit improvement of the mechanical properties of materials for making them suitable in different applications $[1,2]$. Recently, aluminum (Al) and titanium (Ti) with its alloys (Silicon Carbon) are widely used for variety applications like robot parts, precision equipment parts, semiconductor equipment parts and turbine blades. The material properties of the $\mathrm{Al} / \mathrm{SiC}$ and $\mathrm{Ti} / \mathrm{SiC}$ metal matrix composites take advantages in relation to the various material mixes due to their high strength-to-weight ratio, excellent resistance, very good mechanical properties and low toxicity [3].

In the present time many of the advanced materials have been fabricated by using Self-propagating high temperatures synthesis (SHS). SHS method has a very wide range of applications. SHS is a simply and novel method for making certain metal, ceramics, composites and intermetallic compounds by using burning furnace. It has been used to produce a wide variety of materials by including carbides, catalysts and carriers characterized in high activity and selectivity with high physical and mechanical properties [4, 5]. The process is based on a system that involves an exothermic combustion. The application of SHS method for composite materials is appropriate due to combination of several different elements in composite materials. All the elements in composite materials have different melting temperatures and the differences is too wide. Based on it, recent research work has used SHS method to unify elements that have wide melting temperature differences [6].

In the previous research work we have seen that $\mathrm{Al}$ and $\mathrm{Ti}$ have advantages in their use as a matrix [1,7]. Furthermore, Al-alloys have been used in the commercial applications for high strength-to density ratio due to high mechanical properties [7]. For the powder form, Al was compatible to merged by another materials. Whereas in the position on the matrix, Al based composite, it can be replaced by Ti based composite due to the similarity in characteristics [8-10].

In the present investigation we will determine the exothermic reaction of $\mathrm{Ti} / \mathrm{SiC}$ by using the SHS method. Titanium powder $(\mathrm{Ti} / \mathrm{p})$ has been received from Indonesian Power Company Ltd. $\mathrm{Ti}$ and $\mathrm{SiC}$ powder mixture was mechanically activated by attrition mill. It will be expected that $\mathrm{Ti} / \mathrm{SiC}$ can bind to each other to form the composite compound. Hardness testing and Scanning Electron Microscope (SEM) tracing were carried out. The obtained results of $\mathrm{Ti} / \mathrm{SiC}$ by using SHS method have been compared with the other composite materials by using the same SHS method [11]. Research on Ti/SiC enhancement has been based 
on Metal Matrix Composite (MMC) [12]. The novelty of this research work is focused on the substitution of the Al with Ti based composite due to their good mechanical properties and low-cost composite materials fabrication.

\section{MATERIALS}

Titanium powder $(\mathrm{Ti} / \mathrm{p})$ with average particle size of 100 $\mu \mathrm{m}$ was received from Indonesian Power Company Ltd and Silicon carbide (SiC) had particle size in the range of 100-320 $\mu \mathrm{m}$. Ti and $\mathrm{SiC}$ powder mixture was mechanically activated by attrition mill. The grain size after attrition milling was decreased until $\sim 70-100 \mathrm{~nm}$. The volume fractions used in the MMC without wetting agent and catalyst was $70: 30 \%$ and the volume fraction for other composites were: $60: 40 \%$. Figure 1 depicts the form of the mold that has been used for powder pressing and the powder solids.

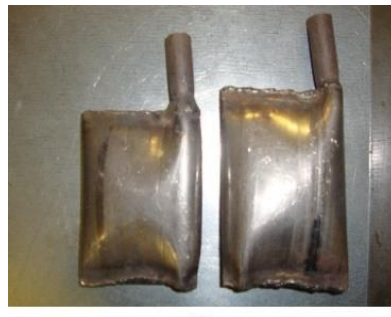

a

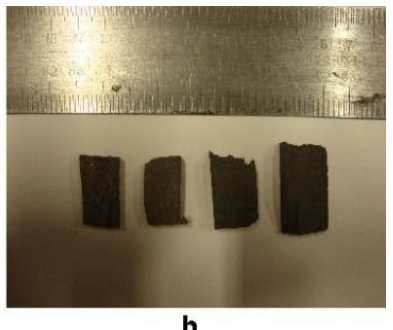

Figure 1. a). Dies of powder compaction; b). SHS solid powder

The refining process is carried out in order to obtain a uniform distribution of powder for sample making and a solid sample will be obtained when the compacting process is carried out. Due to the size adjustment of the sample a gradual sieving process is required for powder refinement in the sample (80-360 mesh). To obtain samples that meet the above requirements, the powder crushing process has been used in order to get an even distribution where a solid sample will be obtained. The ignition temperature of SHS-process was around $900 \pm 120^{\circ} \mathrm{C}$ and then increased during the SHS process up to $1100 \pm 20^{\circ} \mathrm{C}$ for the used powders content $[11,12]$. When the refining process is carried out the distribution of the powder is uniform and afterward, we can obtain a solid sample.

\section{EXPERIMENTAL METHODS}

Figure 2 depicts SHS experimental device for fabrication of the $\mathrm{Ti} / \mathrm{SiC}$ metal matrix composites.

Fine powders with a size of $100 \mu \mathrm{m}$ were subjected to a mixing process of the sample materials used $(\mathrm{Ti} / \mathrm{SiC})$. The mixing process aims to make a uniform powder size in order to obtain a solid sample. Afterward with a solid sample it is hoped that during the SHS process the bonding particles between $\mathrm{Ti} / \mathrm{SiC}$ powders becomes tight. Powder weighing is adjusted according to the size of each volume fraction determined with ratio $70: 30 \%$ for $\mathrm{Ti} / \mathrm{SiC}$ and $60: 40 \%$ for $\mathrm{Ti} / \mathrm{SiC}$.

The dies preparation for the powder has been carried out through compacting process by beginning with cleaning mold with gas and a compressor. Furthermore, the compacted powder has not been contaminated with other elements. Measurement of the frame precision on the mold is accompanied by a marking on the ejector where the time of mold compacting does not slip and the sample is easily to removed. Coating of the mold cavity has been realized through a stearic acid type lubricant where the compacting and pressing process can be done easily without any obstacles.

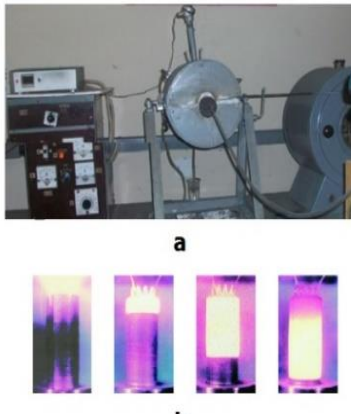

b

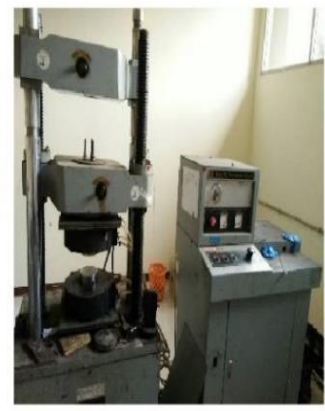

Figure 2. SHS experimental device: a). Heating furnace b). The SHS sample was heated c). Compaction machines

\section{RESULTS AND DISCUSSIONS}

\subsection{Scanning electron microscopes}

SEM observations on samples of $\mathrm{Ti} / \mathrm{SiC}$ composites has been used to have the best mechanical properties. The results of SEM observations were carried out on specimens with a temperature of $900^{\circ} \mathrm{C}$ because these variables were able to produce good mechanical properties, as shown in Figure 3.

The SEM images show that the titanium alloy matrix occupies the largest area (due to the dominant volume fraction), while the shiny white reinforcement is randomly distributed. Microstructure observations were carried out on the sample resulting from the compacting process to determine the effect of sintering temperature variations on the pore size of the sample. Constant high compaction will reduce the number of pores if there is movement of silicon carbide particles which can reduce the number of pores but as the sintering temperature increases the movement of silicon carbide particles decreases and the results in pore formation decreases mechanical properties. In the results of microstructure photos by using SEM depicts that in the compacting with sintering temperature variations we have three elements such as alloy titanium (Ti), silicon ( $\mathrm{Si}$ ), and silicon carbide ( $\mathrm{SiC})$. Phase tests contained in the elements in this composite material were carried out by using $\mathrm{x}$-ray diffraction (XRD) and are shown in the Figure 4.

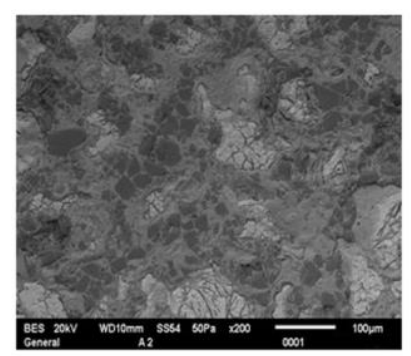

a

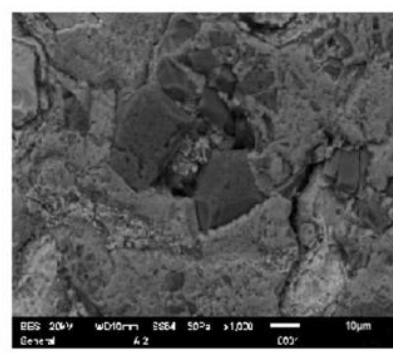

b
Figure 3. Result of scanning electron microscopy (SEM) on $\mathrm{Ti} / \mathrm{SiC}$ based composites a). sizes of $100 \mu \mathrm{m} \mathrm{b}$ ). Sizes of 10 $\mu \mathrm{m}$ 
The shiny white element has been seen in the reinforce of silicon carbide $(\mathrm{SiC})$. The gray element is a matrix of the titanium (Ti) alloy. Based on the below XRD results, it can be seen that the possible phases formed in this section are the phases of the titanium alloy matrix (Ti) and silicon carbide (SiC) reinforcement. Figure 3a shows the distribution phase which is evenly distributed between $\mathrm{Ti}$ as matrix and $\mathrm{SiC}$ as reinforcement. The ties at the grain boundaries look tight and neat. However, it can be seen in Figure $3 b$ that there were some grains of $\mathrm{SiC}$ locked between the grain boundaries of the $\mathrm{Ti}$ phase, this can result in stress concentrations that make the distribution of mechanical properties uneven.

\subsection{The Result of X-ray diffraction (XRD) observation}

Through X-ray diffraction (XRD) observations, it has been shown the diffraction pattern of $\mathrm{Ti} / \mathrm{SiC}$ alloys after 1 -hour heating with a temperature of $900^{\circ} \mathrm{C}$ and it can be seen that the dominant phase is formed $\mathrm{TiO}_{2}$ for each heating. $\mathrm{TiO}_{2}$ phase for all heating has a tetragonal structure at an angle of 27.68; 36,$281 ; 41.5 ; 44.22 ; 54.55 ; 56,835 ; 62,833 ; 64.26 ; 65.84$; 69,$167 ; 69,903$; and 76,858 . The intermetallic phase formed after heating is $\mathrm{TiC}$. It has a cubic structure at heating $900^{\circ} \mathrm{C}$ with an angle of $35.946 ; 41.5 ; 60,246 ; 71,983$; and 76,858 , and $\mathrm{Ti}_{5} \mathrm{Si}_{4}$ has an orthorhombic structure correspond to data no. 231079 on heating $900^{\circ} \mathrm{C}$ with an angle of 37,$111 ; 37,412$; 37,$781 ; 39.49 ; 43,019 ;$ and 44,224 . However, after heating the Ti element correspond with an angle of $35.273 ; 38,371 ; 39,963$; 52,$192 ; 62,833 ; 69,903 ; 75,422 ;$ and 76,858 , and $\mathrm{SiC}$ correspond Figure 4 with an angle of 34,$342 ; 35,946 ; 38,371$; $41.5 ; 60,246 ; 65.84 ; 71,983$; and 75,422, are still formed with the same structure, namely hexagonal. Based on the results of the XRD test, it was found that the dominant $\mathrm{TiO}_{2}$ phase was formed due to the heating of the sample taking place in a nonvacuum furnace where the atmospheric effect in this case was that oxygen had an effect on the formation of the crystal phase. The mechanism is that oxygen molecules from the atmosphere when they reach the surface of the metallic glass will absorb quickly. Then there is the separation of the oxygen molecules into oxygen ions. With increasing temperature, the thermal energy received by the alloy also increases and this energy is used by the alloy to react with the atmosphere (oxygen) to form oxides. The size of the crystal grain with the addition of temperature increases and some decreases. The higher the temperature given the greater the size of the crystals formed.

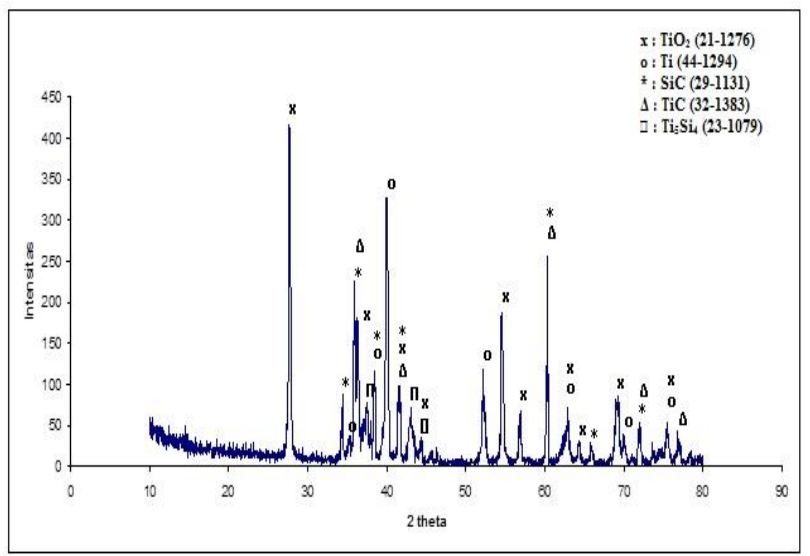

Figure 4. XRD observation results (x-ray diffraction). The compound that was formed: $\mathrm{TiO}_{2}, \mathrm{Ti}, \mathrm{SiC}, \mathrm{TiC}$ and $\mathrm{Ti}_{5} \mathrm{Si}_{4}$

\subsection{Mechanical properties}

Data on the results of several tests such as density is affected by the SHS temperature. The density decreases with increasing SHS operating temperatures. The greater of temperature causes the density of powder particles to be formed where the compacted titanium powder is able to fill the pores between the silicon carbide particles. The easier is that the silicon carbide particles fill the pores between the titanium will cause an increasement in the density of the material.

The optimal density results were achieved at volume fraction of $70: 30 \%$ in SHS temperature of $1000{ }^{\circ} \mathrm{C}$ at 4.54 $\mathrm{gr} / \mathrm{cm}^{3}$. Keeping the lowest density in the volume fraction it cannot bind to a sintering temperature of $1100^{\circ} \mathrm{C}\left(4.46 \mathrm{~g} / \mathrm{cm}^{3}\right)$ and the smallest density at a volume fraction of $60: 40 \%$ with a temperature of $1000^{\circ} \mathrm{C}\left(4.23 \mathrm{gr} / \mathrm{cm}^{3}\right)$. Porosity is a gas or air trapped in the microstructure of the materials where the porosity affects the mechanical properties of $\mathrm{Ti} / \mathrm{SiC}$ composites. Porous structures result in decreased mechanical properties when compared to denser structures [12]. Porosity is caused by shrinkage of the captured gas due to differences in temperature and pressure. Shrinkage occurs in compression when a compacting process is carried out [13] due to the material transition temperature which is the main source of porosity formation. This results from a reduction in volume followed by compaction due to compacting. Meanwhile, gasinduced porosity results from changes in temperature in the microstructure of the materials $[14,15]$. The porosity test data showed that the porosity value increased along with the increasement of the SHS sintering temperature. The lowest porosity was produced at a volume fraction of $70: 30 \%$ with a sintering temperature of $900^{\circ} \mathrm{C}$, namely $2.36 \%$. The largest porosity was produced at a volume fraction of $60: 40 \%$ with a sintering temperature of $1000^{\circ} \mathrm{C}$, namely $5.85 \%$. With the increasing number of $\mathrm{Ti} / \mathrm{SiC}$ to fill the cavities between particles the denser will be the compacted powder particles. The results of reduced porosity are shown in the Figure 5.

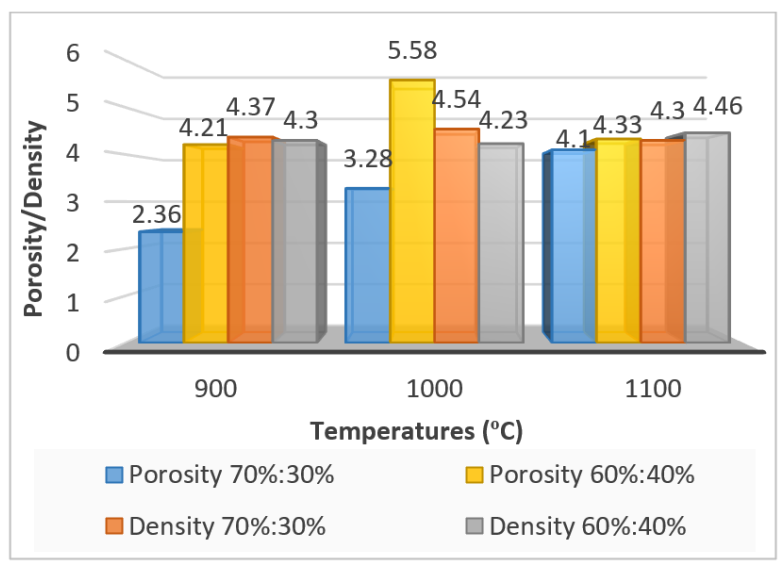

Figure 5. The effect of volume fraction and sintering temperature on the density and porosity of $\mathrm{Ti} / \mathrm{SiC}$ composites

Figure 6 depicts the hardness value results of the $\mathrm{Ti} / \mathrm{SiC}$ based composites. The hardness by volume fraction of $70: 30 \%$ with a maximum SHS sintering temperature reaching $1000^{\circ} \mathrm{C}$, was $40 \mathrm{HV}$ it tends to decrease. The highest hardness was achieved at a volume fraction of $70: 30 \%$ with a sintering temperature of $900^{\circ} \mathrm{C}$, namely $194 \mathrm{HV}$. This was because of $\mathrm{Ti}$ forms a smooth, protective layer $\mathrm{TiO}_{2}$ and $\mathrm{Ti}_{5} \mathrm{Si}_{4}$ as well on its surface. This prevents oxidation and corrosion inward. 
Based on field experiments when Ti heating reaches $1000^{\circ} \mathrm{C}$, the phenomenon that occurs is the occurrence of $\mathrm{TiO}$ and $\mathrm{Ti}_{2} \mathrm{O}$ skin layers, while the hydrogen formed from water vapour in the air is absorbed by Ti. Furthermore, O and N. Basically, hardness is influenced by the bonds of each interface between the matrix and the reinforcement. Hardness is formed from the bonding of materials. With increasing strength, the bonding of the material also increases according to Refs. [16-20]. Strengthening hardness is caused by precipitates or reinforcement in the microstructure of the composite material. With the presence of a reinforcement, it is able to withstand the movement of the dislocation which can increase the hardness of $\mathrm{Ti} / \mathrm{SiC}$ composites.

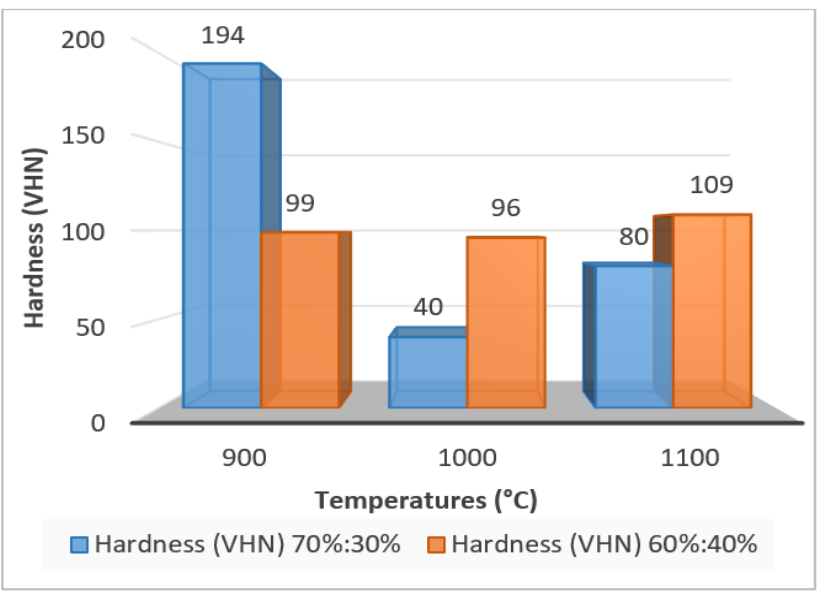

Figure 6. The results of Hardness (HV) Ti/SiC-based composites

\section{CONCLUSIONS}

In the present paper we have briefly described the fabrication of the $\mathrm{Ti} / \mathrm{SiC}$ by using SHS method. It has been seen that the matrix of the Titanium alloy occupies the largest area due to the dominant volume fraction while the shiny white reinforcement is randomly distributed. An Optimal density, porosity and hardness value of $\mathrm{Ti} / \mathrm{SiC}$ are as follows.

The optimal density results were achieved in the volume fraction of $70: 30 \%$ at $1000^{\circ} \mathrm{C}$ for $4.54 \mathrm{gr} / \mathrm{cm}^{3}$. The lowest density was in the volume fraction which cannot bind to a sintering temperature of $1100^{\circ} \mathrm{C}\left(4.46 \mathrm{~g} / \mathrm{cm}^{3}\right)$ and the smallest density at a volume fraction of $60: 40 \%$ with a temperature of $1000^{\circ} \mathrm{C}\left(4.23 \mathrm{gr} / \mathrm{cm}^{3}\right)$.

The lowest porosity was produced at a volume fraction of $70: 30 \%$ with a sintering temperature of $900^{\circ} \mathrm{C}$, namely $2.36 \%$. The largest porosity was produced at a volume fraction of 60 : $40 \%$ with a sintering temperature of $1000^{\circ} \mathrm{C}$, namely $5.85 \%$.

The lowest hardness value was $40 \mathrm{HV}$ and correspond to the volume fraction of $70: 30 \%$ with sintering temperature $1000^{\circ} \mathrm{C}$. The highest hardness was achieved at the volume fraction of $70: 30 \%$ with a sintering temperature of $900^{\circ} \mathrm{C}$ and correspond to $194 \mathrm{HV}$.

The results have shown that we can substitute $\mathrm{Al}$ with $\mathrm{Ti}$ based composite due to very good mechanical properties of the $\mathrm{Ti} / \mathrm{SiC}$ composite materials that are close to our previous research work on mechanical properties of $\mathrm{Al} / \mathrm{SiC}$ composite materials by using SHS method. The future research work would reveal on the enhancement of the mechanical properties of $\mathrm{Ti} / \mathrm{SiC}$ through SHS method.

\section{ACKNOWLEDGMENT}

This work was an independent fund development supported by Department Metallurgy - Faculty of Engineering, Universitas Sultan Ageng Tirtayasa for supporting this research project.

The partially support by the Ministry of Education, Youth and Sports of the Czech Republic and the European Union (European Structural and Investment Funds - Operational Programme Research, Development and Education) in the frames of the project "Modular platform for autonomous chassis of specialized electric vehicles for freight and equipment transportation," Reg. No. CZ.02.1.01/0.0/0.0/16_025/0007293.

\section{REFERENCES}

[1] Pramono, A., Sulaiman, F., Alfirano, A., Suryana, S., Milandia, A. (2020). Characteristics of hybrid composite from hydroxyapatite/metal powder and ceramic. VANOS Journal of Mechanical Engineering Education, 5(2): 109-116. http://jurnal.untirta.ac.id/index.php/vanos

[2] Pramono, A., Kommel, L., Kollo, L., Veinthal, R. (2016). The aluminum based composite produced by self propagating high temperature synthesis. Materials Science, 22(1): 40-43. https://doi.org/10.5755/j01.ms.22.1.7500

[3] Shamsipur, A., Kashani-Bozorg, S., Zareie-Hanzaki, A. (2012). Fabrication of the $\mathrm{Ti} / \mathrm{SiC}$ nano-composite layer by friction stir processing. International Journal of Modern Physics: Conference Series, 5: 367-374. https://doi.org/10.1142/S2010194512002243

[4] Agrafiotis, C.C., Zaspalis, V.T. (2004). Self-propagating high-temperature synthesis of MnZn-ferrites for inductor applications. Journal of Magnetism and Magnetic Materials, 283(2-3): 364-374. https://doi.org/10.1016/j.jmmm.2004.06.054

[5] Aminika, B. (2012). Investigation of the pre-milling effect on synthesis of nanocrystalline $\mathrm{TiB}_{2}-\mathrm{TiC}$ composite prepared by SHS method. Science Direct Powder Technology. 232: 78-86. http://dx.doi.org/10.1016/j.powtec.2012.07.058

[6] Halverson, D.C. (1989). Processing of boron carbidesaluminum composites. Journal of the American Ceramic Society, 72(5): 775-780. http://dx.doi.org/10.1111/j.1151-2916.1989.tb06216.x

[7] Pramono, A., Lauri, K., Kaspar, K., Renno, V., Jaana K.G. (2020). Effect of pressure distribution on hydroxyapatite (HAp) based hybrid composites made from the milkfish bones. Materials Science Forum, 988: 182-191. https://doi.org/10.4028/www.scientific.net/MSF.988.18 2

[8] Xanthopoulou, G. (1999). Oxide catalysts for pyrolysis of diesel fuel made by self-propagating high-temperature synthesis. Part I: Cobalt-modified Mg-Al spinel catalysts. The Journal of Applied Catalysis: A General, 182(2): 285-295. https://doi.org/10.1016/S0926860X(99)00023-X

[9] Pramono, A., Sulaiman, F., Suryana., Milandia, A. (2019). Calcination process on chanos chanos forsk (CCF) of milkfish bones to get hydroxyapatite (HAp) as composites application. IOP Conf. Series: Materials 
Science and Engineering. 532(1): 1-9. https://doi.org/10.1088/1757-899X/532/1/012004

[10] Pramono, A., Milandia, A., Dhoska, K., Kommel, L. (2018). Properties of metal matrix composites by pressureless infiltration (PRIMEXX). In Proceedings Book of the 8th Annual Basic Science International Conference. Malang, pp. 272-279.

[11] Pramono, A., Sulaiman, F., Alhamidi, A.A., Milandia, A. (2020). Fabrication of the $\mathrm{Ti} / \mathrm{SiC}$ based composites by self-propagating high temperature synthesis. International Journal of Innovative Technology and Interdisciplinary Sciences, 3(4): 513-520. https://doi.org/10.15157/IJITIS.2020.3.4.513-520.

[12] Pramono, A., Fiftyandi, A.F., Sulaiman, F., Milandia, A. (2021). Processing of milkfish bone on $\mathrm{Al} / \mathrm{Ti} / \mathrm{Mg}$ into hybrid composites by self-propagating high temperature synthesis (SHS). In 2nd and 3rd International Conference on Food Security Innovation (ICFSI 2018-2019), pp. 279-283. https://doi.org/10.2991/absr.k.210304.053

[13] Kommel, L., Traksmaa, R., Kimmari, E. (2003). Influence of binder composition and microhardness on wear properties of light weight composites. Powder Metallurgy Progress, 3(3): 140-145.

[14] Callister, W.D. (2000). Fundamentals of Materials Science and Engineering. London: Wiley. https://doi.org/10.1007/3-540-36277-0_17

[15] German, R.M. (1984). Powder Metallurgy Science Metal Powder. Industries Federation.
[16] Dhoska, K., Pramono, A., Spaho, E. (2018). Characterization of metal matrix composite by increasing magnesium content. In 17th International SymposiumTopical Problems in the Field of Electrical and Power Engineering, pp. 14-15.

[17] Pramono, A., Kollo, L., Kallip, K., Veinthal, R., Gomon, J.K. (2014). Heat treatment of ultrafine grained highstrength aluminum alloy. In Key Engineering Materials, 604: 273-276. https://doi.org/10.4028/www.scientific.net/KEM.604.27 3

[18] Pramono, A., Dhoska, K., Alhamidi, A., Trenggono, A., Milandia, A. (2019). Investigation of mechanical properties on composite materials by several of severe plastic deformation (SPD) methods. In IOP Conference Series: Materials Science and Engineering, 673: 012120. https://doi.org/10.1088/1757-899X/673/1/012120

[19] Pramono, A., Yolanda, A., Alhamidi, A.A. (2019). Preheating of multi-axial forging (MAF) on aluminum based composites. In IOP Conference Series: Materials Science and $\quad$ Engineering, $478(1)$ : 012029. https://doi.org/10.1088/1757-899X/478/1/012029

[20] Pramono, A., Dhoska, K., Markja, I., Kommel, L. (2019). Impact pressure on mechanical properties of aluminum based composite by ECAP-parallel channel. Pollack Periodica, 14(1): 67-74. 